\title{
Educación interactiva a través de narrativas transmedia: posibilidades en la escuela
}

Interactive Education through Transmedia Narratives: Possibilities at School

Education interactive à travers les récits transmedia: les possibilités à l'école

Educação interativa por meio de narrativas transmídia: possibilidades na escola

Fecha de recepción: 15 DE MARZO DE 2016/Fecha de aceptación: 12 DE SEPTIEMBRE DE 2017/Fecha de disponibilidad en línea: 15 DE ABRIL DE 2018

Encuentre este artículo en http://magisinvestigacioneducacion.javeriana.edu.co/

\section{Resumen}

El artículo presenta parte de los resultados de una investigación que indagó las formas de interactividad alcanzadas por estudiantes de básica primaria y secundaria de Bogotá, en ambientes que fomentaron estilos comunicativos todostodos, y cuyos contenidos de aprendizaje se basaron en la producción participativa de narrativas transmedia. Además de exponer los referentes teóricos del trabajo, se expone la metodología de la investigación, la cual se apoyó en el enfoque cualitativo y en la etnografía convencional y virtual. Al final se analizan los resultados, haciendo énfasis en la importancia de la comunicación bidireccional al trabajar con contenidos digitales, y en el uso de técnicas como la remediación y la hibridación en la construcción de narrativas transmedia.

\section{Palabras claves}

Educación; comunicación; educación interactiva;

interactividad; narrativa transmedia

Para citar este artículo / To cite this article / Pour citer cet article / Para citar este artigo

Amador-Baquiro, Juan Carlos (2018). Educación interactiva a través de narrativas transmedia: posibilidades en la escuela. magis, Revista Internacional de Investigación en Educación, 10 (21), 77-94. doi: 10.11144/Javeriana.m10-21.eint 


\section{Keywords}

Education; communication; interactive education; interactivity; transmedia narrative

\section{Mots clés}

Education ; communication ; éducation interactive ; interactivité ; récit transmedia

\section{Abstract}

The article presents part of the results of a research that investigated the ways interactivity was achieved by primary and secondary school students in Bogotá, in environments that encouraged many to many communication styles, and whose learning contents were based on the production of narratives transmedia. The theoretical references of the work and the methodology of the research are exposed. The paper follows a qualitative approach and conventional and virtual ethnography. Results were analyzed, emphasizing the importance of bidirectional communication when working with digital content, and the use of techniques such as remediation and hybridization in the construction of transmedia narratives.

\section{Résumé}

L'article présente en partie les résultats d'une recherche qui a enquêté les formes d'interactivité réussis par les étudiants de l'école primaire et secondaire à Bogota, aux environnements qui encouragent les styles communicatives tous-tous; et dont les contenus d'apprentissage se sont basés sur la production participative de récits transmedia. Par ailleurs, on expose les référents théoriques du travail, on présente la méthodologie de la recherche, laquelle utilise la perspective qualitative et l'ethnographie conventionnelle et virtuelle. Enfin, on analyse les résultats, on insiste sur l'importance de la communication bidirectionnelle au travail avec les contenus numériques, et dans l'usage de techniques tels que la remédiation et l'hybridation dans la construction de récits transmedia.

\section{Palavras-chave}

Educação; comunicação; educação interativa; interatividade; narrativa transmídia

\section{Resumo}

O artigo apresenta parte dos resultados de uma pesquisa que indagou as formas de interatividade alcançadas por estudantes de ensino fundamental e médio de Bogotá, em ambientes que fomentaram estilos comunicativos todos-todos, e cujos conteúdos de aprendizagem se basearam na produção participativa de narrativas transmídia. Além de expor os referentes teóricos do trabalho, expõe-se a metodologia da pesquisa, que se apoiou no enfoque qualitativo e na etnografia convencional e virtual. Ao final analisam-se os resultados, dando ênfases à importância da comunicação bidirecional ao trabalhar com conteúdos digitais, e no uso de técnicas como a remediação e a hibridação na construção de narrativas transmídia. 


\section{Introducción}

La relación entre comunicación y educación ha sido un objeto de investigación central en las pedagogías críticas y en los llamados estudios culturales latinoamericanos (Huergo, 2000; Kaplún, 1998; Martín-Barbero, 2003; Orozco-Gómez, 2010). Algunos de sus planteamientos coinciden en mostrar cómo algunos discursos y prácticas de la pedagogía moderna, que llegan hasta la actualidad, continúan anclados en el modelo de comunicación de masas (mass media), basado en la acción de un emisor y el rol pasivo de varios receptores, por medio del broadcast. Según Mario Kaplún (1998), este modelo ha sido implementado con dos grandes estrategias: la transmisión de contenidos y el entrenamiento (instruccional) para garantizar óptimos desempeños académicos en los alumnos ${ }^{1}$. Lo paradójico de esta permanencia en el tiempo es que, desde finales del siglo $\mathrm{XX}$, el modelo de comunicación de masas está transitando progresivamente hacia estilos predominantemente digitales e interactivos (Aparici, 2010; Lévy, 2007; Scolari, 2008).

Mientras que las prácticas comunicativas emergentes, en la actual cultura digital, progresivamente se están apoyando en formatos como el hipertexto, la hipermedia y la narrativa transmedia, tanto en la esfera del consumo como en la producción de medios y contenidos, las prácticas pedagógicas en el mundo escolar operan a partir de tres lógicas predominantes. En primer lugar, los contenidos escolares empleados tienden a ser tramitados con mensajes cerrados, lineales y secuenciales. En segundo lugar, el emisor principal (profesor) generalmente funge como un presentador que busca atraer la atención del receptor (por seducción y/o imposición) basado en su universo cultural e ideológico. Por último, se presume que los estudiantes deben comportarse como receptores pasivos, capaces de asimilar los mensajes tal como se enseñan (Aparici \& Silva, 2012).

A lo largo del siglo XXI han surgido perspectivas que buscan articular la comunicación digital interactiva con la educación (Cabero, 2001; Lacasa, 2011; Rueda-Ortiz, 2009). A partir de referentes procedentes de investigadores y activistas de la cibercultura, se han abierto paso nuevos conceptos y propuestas que evidencian la necesidad de replantear las prácticas educativas desde una nueva lógica de comunicación. A manera de ilustración, se destacan perspectivas como la educación expandida (Proyecto Zemos98), el aprendizaje invisible (Cobo-Romaní \& Moravec, 2010), el aprendizaje ubicuo (Burbules, 2006), la educación en la frontera emocional (Ferrés, 2008), el proyecto posuniversidad y edupunk (Piscitelli, 2009), la educación, las pantallas y las transmediaciones (Orozco-Gómez, 2010),

1 En esta generación de pioneros del campo Comunicación-Educación, se destacan tres debates fundamentales. En primer lugar, Jesús Martín-Barbero (2003) y Guillermo Orozco-Gómez (2010) coinciden en analizar estos fenómenos a partir del concepto de mediaciones, comprendidas como procesos relacionales entre medios, sujetos y grupos, los cuales modifican, a partir de usos y apropiaciones, tanto la subjetividad como los objetos. En segundo lugar, Jorge A. Huergo (2000) evidenció hacia inicios de 2000 la existencia de tensiones entre la cultura mediática y la cultura escolar, y mostró la necesidad de problematizar el campo Comunicación-Educación alrededor de cuatro aspectos claves: lo comunitario, lo institucional lo mediático y las tecnologías de información y comunicación en el escenario escolar. Por último, Guillermo Orozco-Gómez (2010) e Inés Dussel y Daniela Gutiérrez (2006) plantean la necesidad de emprender nuevas alfabetizaciones en los procesos de formación, a partir de reconocimiento de una lógica mediática y un régimen visual que conviven con el orden social, la política y la cultura de las sociedades contemporáneas. Esto no solo implica introducir las tecnologías de información y comunicación en las escuelas o universidades para reproducir las prácticas y los currículos convencionales, sino generar las condiciones para leer críticamente los medios y las tecnologías digitales, interpretar sus códigos y producir contenidos de modo que favorezcan el diálogo hacia dentro y hacia fuera de la institución educativa.
Descripción del artículo | Article description | Description de l'article Artigo descrição

Este artículo de investigación, derivado del proyecto Narrativas audiovisuales y educación en contextos de conflicto armado en Colombia, indagó los grados de interactividad alcanzados por estudiantes de colegios de Bogotá cuando producen narrativas transmedia. Los resultados muestran, en reación con los estilos comunicativos, que los estudiantes logran mejores niveles de bidireccionalidad cuando trabajan con contenidos digitales en los que se combinan textos alfabéticos, imágenes y sonoridades. Y, en relación con los contenidos escolares, el estudio evidencia que, al abordar diversas textualidades, con técnicas como la remediación y la hibridación, los estudiantes logran transitar de la mecanización de contenidos a la adquisición del sentido mediante la producción de narrativas. 
las alfabetizaciones para educar la mirada (Dussel \& Gutiérrez, 2006) y los videojuegos y la educación (Lacasa, 2011)2.

Basados en lo anterior, y teniendo en cuenta la diversidad de escenarios en los que ocurre la educación, especialmente en espacios como la escuela, se requiere repensar los procesos educativos, específicamente los currículos, las prácticas pedagógicas y la evaluación del aprendizaje, en torno a dos aspectos claves que surgen de este panorama: otros estilos comunicativos que deberían ser considerados para orientar las prácticas pedagógicas; y tipos de textualidades (alfabéticas, visuales, sonoras, audiovisuales, digitales) que podrían favorecer la construcción y expansión de contenidos escolares más flexibles y abiertos para el desarrollo de determinados aprendizajes en los estudiantes.

Tanto los estilos comunicativos emergentes como los contenidos multimodales que actualmente se producen, circulan y apropian en la cultura digital, se inscriben en la dinámica predominantemente interactiva de los medios digitales contemporáneos. Estos medios - además de incorporar lo virtual y lo digital como parte de su arquitectura y funcionamiento, y como elementos constitutivos de los ecosistemas sociotécnicoculturales contemporáneos (Medina, 2007) - aportan poderosamente a la configuración de una cultura que reconfigura las formas de ser, pensar y actuar de las personas. Esta nueva manera de hacer aprehensible la realidad, resolver problemas y generar proyectos comunes es para Pierre Lévy (2007) una expresión de la inteligencia colectiva, mientras que para Henry Jenkins (2008) es la base de una nueva cultura de participación.

La educación interactiva (Aparici \& Silva, 2012; Silva, 2005) $)^{3}$ es una posibilidad para implementar nuevos estilos comunicativos y desplegar contenidos

2 Varios de estos trabajos cuentan con respaldo investigativo y sus contribuciones han sido claves para el desarrollo de algunas teorías y de experiencias pedagógicas en casos excepcionales. Sin embargo, en otros casos se encuentran posturas celebratorias alrededor de las novedades de la cultura digital y compromisos explícitos con el mercado, pues no es un secreto que las corporaciones dedicadas a la venta de tecnologías móviles, servicios de internet y contenidos de entretenimiento patrocinan investigaciones, orientadas a mostrar las bondades de sus ofertas, a la vez que profundizan en el imaginario de las nuevas generaciones con facultades naturalizadas, las cuales aprenden de otra manera y desestabilizan las condiciones de formación de la escuela y la universidad modernas.

3 Temprano, el constructivismo analizó el carácter interactivo y dinámico del sujeto en su aprendizaje. Específicamente, alrededor de los procesos de asimilación, acomodación y equilibración, autores como Jean Piaget sostienen que el desarrollo psicobiológico y las condiciones del ambiente hacen posible la consolidación de las estructuras de pensamiento en el niño. Por su parte, algunos representantes de la Escuela Nueva, como Ovide Decroly y John Dewey, destacan la interacción y la experiencia como elementos centrales en la adquisición de aprendizajes en los niños, en la formación para la vida y el nosotros (Gadotti, 2011). de aprendizaje multimodales y abiertos en la escuela, en el contexto de estas expresiones de inteligencia colectiva y de cultura participativa. Según sus proponentes, este tipo de educación cuenta con tres características: el aprendizaje se construye mediante una relación dialógica que asocia emisión y recepción como polos antagónicos y, a la vez, complementarios en la creación de la comunicación y del aprendizaje; los estudiantes trabajan con los contenidos de aprendizaje como puntos de partida y no como puntos de llegada, construyendo así sus propios mapas de conocimiento y dirigiendo sus propias exploraciones; y por último, el profesor propone el conocimiento como un arquitecto de recorridos, pues no lo transmite ni lo ofrece a distancia para la recepción sedentaria y pasiva de sus estudiantes ${ }^{4}$.

El escenario digital es un campo de posibilidades para el despliegue de la educación interactiva a partir de dos aspectos claves: los ambientes y las narrativas. Los primeros pueden ser de carácter online u offline, lo importante es que otorguen grados de libertad para que los sujetos que participen puedan habitarlos en espacios y tiempos flexibles, heterogéneos y abiertos. Por su parte, las narrativas se comprenden como producciones socioculturales que favorecen la creación de mundos posibles, los cuales se construyen y se deconstruyen, con lenguajes alfabéticos y orales, pero también a partir de imágenes fijas y en movimiento, sonidos y animaciones digitales (Amador, 2013)5.

De esta manera, el presente artículo analiza las posibilidades de implementación de algunos elementos de la educación interactiva por medio de narrativas transmedia. Expone parte de los resultados de una investigación cualitativa, apoyada en la etnografía

4 Estas afirmaciones no pretenden desconocer cómo algunas perspectivas pedagógicas consideraron tempranamente el carácter activo, dinámico y participativo del estudiante en el desarrollo de su aprendizaje. No obstante, la educación interactiva, al ubicarse en las coordenadas de la cultura digital contemporánea, busca potenciar nuevos estilos comunicativos y trabajar con lenguajes multimodales en los contenidos de aprendizaje en la escuela.

5 Otro elemento importante a tener en cuenta en este tránsito hacia la comunicación digital es la producción y la organización del texto, el cual se entiende como una composición de signos y codificaciones que trazan unidades de sentido. El texto se ha potenciado hacia nuevas formas de producción, circulación y recepción, específicamente a través del hipertexto, la hipermedia y la transmedia. Mientras que el primero es una estructura secuencial que permite crear, agregar, enlazar y compartir información de diversas fuentes por medio de enlaces asociativos, el segundo comprende una serie de procedimientos para diseñar contenidos soportados en textos, imágenes, videos, audios, mapas, entre otros, los cuales están vinculados, a su vez, a hipermedios conectados en red. Por último, transmedia es un contenido narrativo (storytelling, según Jenkins, 2008) que se despliega por múltiples medios y plataformas de comunicación, y en el cual una parte de los usuarios (consumidores y prosumidores) asumen roles activos durante el proceso de expansión. 
convencional (Guber, 2001) y la etnografía virtual (Hine, 2002), a partir de la implementación de dos experiencias pedagógicas en colegios oficiales de Bogotá. Una de las experiencias se desarrolló con niños y niñas de grado segundo (educación básica primaria). Y la segunda se implementó de manera colaborativa con estudiantes de básica secundaria de tres colegios de manera simultánea.

La pregunta de investigación que guio este estudio fue: ¿Qué posibles formas de interactividad logran estudiantes de básica primaria y secundaria de dos colegios oficiales de Bogotá, en ambientes que fomenten estilos comunicativos todos-todos, y cuyos contenidos de aprendizaje se basen en la producción participativa de narrativas transmedia? En esta dirección, el problema de investigación fue abordado desde dos planos de análisis, entendidos no como categorías deductivas sino como aspectos orientadores del proceso de interpretación de las experiencias pedagógicas implementadas, a partir de las dimensiones constitutivas de la educación interactiva. El primero indagó el estilo comunicativo de la experiencia pedagógica, al analizar los roles de emisores y receptores, y las posibles formas de bidireccionalidad, reticularidad y multitrayectoria de los mensajes. El segundo abordó la estructura de los contenidos. Dado que las experiencias pedagógicas tuvieron como regla de juego el uso y la construcción participativa de narrativas transmedia, se indagó por las condiciones de producción, apropiación y circulación de esos contenidos. También se analizaron las posibilidades de intervenir contenidos mediante remediaciones e hibridaciones. Estos dos planos de análisis serán explicados de manera más detallada en el apartado de metodología.

\section{Referentes conceptuales}

De acuerdo con las condiciones teóricas del problema de investigación, a continuación se presentan, de manera sintética, tres referentes que buscan aportar a una mejor comprensión del objeto de estudio. En primer lugar, se desarrollará el concepto de interactividad y su relación con la interacción con el propósito de mostrar su complementariedad. Luego de esta precisión, se expondrán los aspectos constitutivos de la educación interactiva con el propósito de comprender sus apuestas en cuanto a estilo comunicativo y contenidos de aprendizaje. Por último, se presentarán los rasgos generales de las narrativas transmedia, pues, como se explicó anteriormente, fue el tipo de contenido elegido para el desarrollo de las experiencias en los escenarios educativos seleccionados para la investigación.

\section{La potenciación de interacciones en la educación interactiva}

Según Roberto Aparici y Marco Silva (2012), la interactividad aporta aspectos claves para la configuración progresiva de un estilo comunicativo en la educación, en el que se entrelazan emisión y recepción como forma de cocreación libre y plural en sus participantes. En esta forma de comunicación, el emisor produce mensajes abiertos y susceptibles de ser modificados por sus receptores. Los receptores asumen una posición activa y disponible para la intervención del mensaje, cuyo contenido adopta progresivamente componentes de carácter hipertextual, hipermedial y/o transmedia, lo que favorece la adquisición de grados de libertad de los usuarios para alcanzar diversas formas de interactividad. En adelante, en lugar de emisores y receptores actúan usuarios-actores, y en lugar de mensajes cerrados se configuran contenidos-narrativas (Rodríguez, 2011).

Comprender la potencialidad de la interactividad implica reconocer el valor que contiene el concepto de interacción como aquello que favorece 
la relación del sujeto con el grupo social. Los estudios sobre este concepto se sitúan en teorías de las ciencias sociales que evidencian una suerte de relación inherente con la comunicación humana y social. De allí se desprende que los individuos, comprendidos como seres relacionales, construyen interacciones como parte de sus predisposiciones y motivaciones en la empresa del mundo social ${ }^{6}$. Por su parte, la interactividad suele entenderse como algo que va más allá de las interacciones, y que se potencia gracias al advenimiento de nuevos medios de comunicación, así como a la complejidad (no lineal) que adquieren las relaciones sociales de los actores en el escenario de internet? ${ }^{7}$.

No obstante, siguiendo a Marco Silva (2005), no se trata de asumir la interactividad como un proceso evolutivo (generalmente asociado con el desarrollo tecnológico) que supera a la interacción. Más allá de una disyuntiva entre los dos conceptos, se puede señalar que dados los rasgos que está adquiriendo la comunicación en la actualidad, la interactividad es más bien un proceso de potenciación de las interacciones de los actores sociales. Esto si se tiene en cuenta que el nuevo estilo comunicativo potencia especialmente dos tipos de interacciones: las selectivo-interpretativas, las cuales le permiten al usuario construir sus propias trayectorias de lectura; y las comunicativas, que intensifican los intercambios y diálogos tanto de manera sincrónica como asincrónica.

6 Según George H. Mead (1968), las personas se forman socialmente una vez logran observarse a sí mismos como objetos. Esta objetivación supone salir de su ensimismamiento para explicitar sus intereses, ideas, expectativas, sensaciones y sentimientos. A este proceso de apertura, George H. Mead (1968) le llamó self especular, esto es, aquello que pone en juego cada participante en situaciones comunicativas específicas, a partir de su interacción con otros. Por su parte, Herbert Blumer (1982) planteó tres premisas sobre el interaccionismo. En primer lugar, las personas actúan sobre los objetos e interactúan con otras personas a partir de los significados que estos adquieren para ellas. Esos significados se producen a partir de los símbolos, los cuales trascienden el ámbito de lo sensorial y de lo inmediato. De esta manera, amplían la percepción del entorno, incrementan la capacidad de resolución de problemas y facilitan la imaginación. En segundo lugar, los significados son producto de la interacción social, especialmente de la comunicación, la cual cumple una función esencial, tanto en la constitución del individuo como en la producción social de sentido. El significado está constituido por signos y opera como el indicador social que interviene en la construcción de la conducta. La tercera premisa plantea que las personas seleccionan, organizan, reproducen y transforman los significados en los procesos interpretativos, a partir de sus objetivos y expectativas. Luego, Erving Goffman (2012), con base en el esquema interpretativo de la dramaturgia, analizó los ritos de interacción comunicativa que las personas aprenden y ponen en juego en la vida cotidiana. Planteó el rol como un conjunto organizado de expectativas de comportamiento alrededor de determinadas posiciones sociales. El rol es desempeñado por el actor, mediante procesos de interacción en contextos específicos, en los que generalmente está siendo observado (escenario). Sin embargo, cuando se interactúa en escenarios distintos, los roles se modifican. Por consiguiente, los interlocutores-actores asumen uno o varios roles en la interacción, a partir del marco (situación-tipo) y el escenario, y de la imagen que buscan ofrecer a otros. Finalmente, Erving Goffman (2012) llamó estrategia a los componentes de la interacción que pueden ser previstos, calculados y controlados.

7 Anne Marie Costalat-Founeau (1985 citada por Marco Silva, 2005), hacia la década de 1980, expuso la necesidad de diferenciar la interacción de la interactividad. Para la investigadora francesa, la interacción es restrictiva en la medida en que alude a una concepción de comunicación bilateral y esquemática, mientras que la interactividad refiere a una comunicación discursiva que está orientada por predisposiciones cognitivas o afectivas entre los sujetos que participan en la vida social. Estas predisposiciones surgen de modos de vida interindividuales, los cuales suelen caracterizarse por sus rasgos inestables y caóticos, más que lineales y sistemáticos. Finalmente, con la expansión y popularización de las tecnologías de la información y comunicación, desde la informática y la telemática se consolidó el concepto de interactividad, comprendido como propiedad inherente de lo digital y luego de lo virtual. Al respecto, el término se asoció preliminarmente con la capacidad de los computadores para responder a los requerimientos de los usuarios (Multigner, 1994). Sin embargo, con el surgimiento de la World Wide Web, hacia la década de 1990, la interactividad fue considerada como un atributo emergente de la convergencia tecnológica entre tres sectores: la informática, las telecomunicaciones y los medios de comunicación. 
Esta potenciación de interacciones singulares puede ser comprendida, según Roberto Aparici y Marco Silva (2012), a partir de tres características: la participación-intervención; la bidireccionalidad-hibridación; y la potencialidad-permutabilidad. La primera plantea que participar no es solo responder afirmativa o negativamente, sino elegir alternativas determinadas, e interferir, intervenir en el contenido de la información, e incluso modificarlo. La segunda característica parte de entender la comunicación como producción conjunta de emisión y recepción, esto es un proceso de cocreación, en que se entrecruzan codificaciones y decodificaciones. La tercera plantea que la comunicación se constituye mediante diversas redes asociativas de conexiones. En esta arquitectura reticular y polifónica emergen posibilidades de efectuar cambios, asociaciones y producir múltiples significados.

\section{Educación interactiva}

Uno de los retos de la educación en las sociedades contemporáneas es generar ambientes presenciales o virtuales que favorezcan la comunicación por medio de nuevas organizaciones del espacio y el tiempo, de modo que los participantes cuenten con opciones para potenciar sus interacciones y aprender. Esto significa proponer, diseñar, remediar, implementar y publicar contenidos, entre otras posibilidades.

Este tipo de ambiente es un aspecto clave para la construcción progresiva de una educación interactiva, dirigida a los niños, las niñas y los jóvenes que actualmente transitan por las instituciones educativas formales. Parte de tres condiciones de posibilidad: uno, aceptar que, al participar en la comunicación digital interactiva, los estudiantes pueden potenciar sus percepciones y experiencias sensibles (sensorium) para aprender en calidad de usuarios y/o prosumidores (Piscitelli, 2009); dos, se requiere de una voluntad ética y política del docente para transformar el modelo comunicativo-pedagógico predominante, transitando de la lógica uno-todos a un estilo todos-todos; y tres, es necesario dinamizar el carácter logocéntrico y enciclopédico que ha predominado en la configuración del conocimiento escolar en el tiempo, con conocimientos originados y mediados por múltiples narrativas, entre ellas, las digitales.

La educación interactiva -basada en un estilo de comunicación todos-todos-, además de requerir ambientes que posibiliten otras lógicas para tramitar los espacios y los tiempos en las instituciones educativas, debe resignificar los contenidos con los que se suele enseñar. Esta intención se apoya en una cuidadosa selección de contenidos que inicialmente adelanta el profesor, pero que después se despliega mediante modos de gestión colectiva de conocimiento por parte de los participantes.
Los contenidos generalmente se componen de textos. En la escuela moderna, estos textos suelen ser presentados en lenguajes analógicos $y$, eventualmente, a manera de ilustración o ejemplificación, se acude a imágenes, e incluso a "recursos de internet". Sin embargo, se trata de contenidos estructurados de izquierda a derecha, de arriba hacia abajo y guardando correspondencia con las proporciones de la secuencialidad (edades, grados, niveles...). En una lógica distinta, bajo este estilo de comunicación, es muy importante considerar otro tipo de textos, los cuales generalmente circulan fuera de las instituciones educativas: el hipertexto, la hipermedia y la narrativa transmedia.

\section{Narrativas transmedia}

Transmedia refiere al concepto de narrativa por distintas razones. En primer lugar, alude a una especial forma narrativa que se expande en diversos sistemas de significación verbal, icónica, audiovisual o interactiva y en distintos medios, por ejemplo, el cine, la televisión, el videojuego, el cómic o el teatro (Amador, 2013; Kinder, 1991; Scolari, 2013). Por esta razón, dependiendo del ambiente, surgen relatos, tramas, personajes y desenlaces distintos, sin perder los hilos conductores de una matriz original. Henry Jenkins (2008) denomina este proceso storytelling.

Por otro lado, el carácter narrativo de la obra también tiene que ver con sus propósitos. Transmedia es un proceso que busca recrear la relación de la trama narrativa con las subtramas ocultas, mediante una combinación dinámica de articulaciones de escenas y biografías. Para tal efecto, se emplean medios, géneros y estéticas diversas que expanden (de manera ampliada, remixada o remediada ${ }^{8}$ ) las textualidades de la trama general. Este proceso potencia la pluralidad de representaciones, alcanzando secuencias imprevisibles de experiencias individuales y colectivas. La experiencia puede terminar alterando los contenidos y generando modificaciones en las condiciones de producción, acceso, recepción y participación. Se trata de experiencias que, incluso, pueden ir más allá de lo previsto por los autores.

Por último, se puede concluir que las narrativas transmedia dan cuenta de nuevas textualidades y estéticas. Evidentemente, es un proceso comunicativo en proceso de consolidación que surge como efecto de la convergencia tecnológica y cultural de los medios. Su uso y apropiación potencia nuevas prácticas en los usuarios, quienes ya no solo actúan como receptores y

8 Para Jay David Bolter y Richard Grusin (2000), las remediaciones son manifestaciones humanas (extensiones y sistemas nerviosos) que adquieren trayectorias propias, cuyos contenidos pueden fluir, combinarse, remezclarse y reinventarse. 
emisores sino como comunidades de saber. Aunque hay varias teorías sobre comunidades de aprendizaje y de práctica en la cultura digital, vale señalar que tanto los estilos comunicativos como los contenidos que circulan por estas pueden generar formas de inteligencia colectiva fundamentales para el desarrollo de saberes de distinto tipo y para la gestión de acciones colectivas locales y globales ${ }^{9}$.

\section{Metodología}

Como se mencionó al inicio, la investigación adoptó la etnografía en su versión convencional y en la opción online o virtual. Teniendo en cuenta que el objeto de investigación se pregunta por los grados de interactividad alcanzados por grupos de estudiantes de distintas edades y cursos, en torno a procesos de producción de narrativas transmedia, fue pertinente aplicar la etnografía convencional con el fin de registrar los posicionamientos de los actores en sus espacios habituales, alrededor de las experiencias pedagógicas en mención (Guber, 2001). Esto exigió acompañar el proceso de producción de las narrativas transmedia en los respectivos colegios.

Sin embargo, dado que estas narrativas se producen en ambientes virtuales, preferiblemente online, fue necesario acudir a los criterios y estrategias de la etnografía virtual. En particular, este tipo de etnografía es una perspectiva que problematiza el uso de internet en tres niveles: como forma de comunicación; como objeto cultural dentro de la vida de las personas, lo que conduce a disputas y negociaciones sobre sus significados; y como tiempo-lugar en el que se producen sentidos, traducidos en formas de identidades y subjetividades (Hine, 2002) ${ }^{10}$.

En lo procedimental, la etnografía virtual se llevó a cabo a partir de cinco pasos claves: diseño de un repositorio de información; diseño de subcarpetas en la carpeta de cada colegio, de acuerdo con los dos planos de análisis iniciales (lógica de comunicación — bidireccionalidad, multitrayectoria y reticularidad del mensaje-; y tratamiento de contenidos -interpretación, apropiación, remediación, hibridación-); registro, vía pantallazos (Print Screen, Impr Pant, Imp Pant, ImpPnt o SysRq PrtScn), de las situaciones asociadas con los grados de interactividad en las experiencias pedagógicas; clasificación de los pantallazos registrados en cada carpeta y subcarpeta; exploración de imágenes, fotografías y enlaces a videos y sitios web de los participantes; y registro de evidencias de educación interactiva y transmediación. A continuación se sintetizan los dos planos de análisis seleccionados, su definición y aspectos claves que los constituyen.

9 Las comunidades de práctica (Wenger, 2001) son formas de encuentro, asociación u organización con objetivos precisos. Por lo general, buscan fomentar aprendizajes mediante prácticas compartidas, de tal modo que estas puedan ser confirmadas, socializadas, aprendidas y expandidas. Uno de sus referentes es la participación, comprendida como la generación de eventos de aprendizaje en los que personas y grupos son incluidos porque tienen algo para decir y compartir. No solo se aprende en condición de receptor, sino también expresando y compartiendo lo que se sabe. Por esta razón, las comunidades de práctica fomentan eventos de aprendizaje, esto es, experiencias que incluyen sujetos, comunidades y organizaciones que se inscriben en proyectos comunes.

10 Para Christine Hine (2002), la etnografía virtual replantea la noción de campo (habitual en los estudios etnográficos desde sus orígenes). Si el campo para el etnógrafo tradicional implica insertarse en un espacio físico - local- para comprender los sistemas culturales que produce una comunidad, el campo para la etnografía virtual implica sumergirse en los flujos y conexiones de la Comunicación Digital Interactiva, CDI (Scolari, 2008), como base de reconocimiento de los sistemas simbólicos que le permiten operar como cultura y/o como artefacto cultural. 
Tabla 1

Planos de análisis

\begin{tabular}{l|l|l}
\hline Planos de análisis & Explicación & Aspectos claves \\
\hline Estilo de comunicación & $\begin{array}{l}\text { Este plano explora el estilo comunicativo implementado a partir } \\
\text { de las experiencias. Busca descifrar los roles del profesor y los } \\
\text { estudiantes en torno a la experiencia pedagógica. Aborda los } \\
\text { acuerdos, estrategias y prácticas entre emisores y receptores } \\
\text { (usuarios) para el logro de los propósitos establecidos. Finalmente, } \\
\text { analiza cómo se resuelve la comunicación, en términos de } \\
\text { codificaciones y decodificaciones, alrededor de la producción de } \\
\text { narrativas transmedia. }\end{array}$ & Bidireccionalidad \\
\hline $\begin{array}{l}\text { Tratamiento de } \\
\text { contenidos }\end{array}$ & $\begin{array}{l}\text { Este plano se centra en los contenidos con los que trabajan } \\
\text { estudiantes y profesores para generar procesos de aprendizaje. } \\
\text { Explora si los contenidos escolares son abordados a partir de } \\
\text { distintas fuentes de información (más allá del texto escolar). } \\
\text { Examina si estos contenidos favorecen su interpretación y } \\
\text { apropiación. Problematiza cómo esos contenidos pueden ser } \\
\text { intervenidos (remixados y remediados). Finalmente, analiza si esos } \\
\text { contenidos son divulgados en audiencias interesadas en estos } \\
\text { temas y problemas. }\end{array}$ & Apropiación \\
\hline \hline
\end{tabular}

Fuente: elaboración propia

\section{Resultados}

\section{Cuentos fantasmagóricos}

Esta experiencia surgió de un proyecto de aula gestionado por la profesora titular y los estudiantes del grado segundo de un colegio oficial de Bogotá. El objetivo del proyecto fue potenciar en los niños habilidades de producción narrativa con tecnologías digitales y narrativas transmedia. Producto de sus intereses, la profesora inició con la proyección del filme Hotel Transylvania (Tartakovsky, 2012) ${ }^{11}$. Partiendo de esta narrativa, la cual incluyó contenidos audiovisuales y digitales, la profesora propuso a los niños producir tres tipos de narrativas adicionales. La primera consistió en escribir cuentos que mantuvieran aspectos de la trama narrativa, pero que incorporaran otros personajes, otros problemas y otros finales. Esta producción se adelantó, apoyados en la aplicación Calameo, con la cual los estudiantes lograron articular la escritura analógica con imágenes digitales, procedentes de la web, que acompañaron el relato.

La segunda narrativa se apoyó en el formato video. En esta oportunidad, con la aplicación Storyboard, los niños planearon, produjeron y editaron videos alternativos a la historia original y al cuento propuesto con Calameo $^{12}$. La tercera narrativa, con la aplicación Art Attack, consistió en diseñar "monstruosidades". Para los niños, se trataba de diseñar a su imagen y semejanza uno de los personajes que habían aparecido en el cuento o en el video, pero que se había restringido a las imágenes prediseñadas en las plantillas de las aplicaciones.

11 Se trata de un filme de animación en el que su protagonista, Mavis, hija del conde Drácula, luego de haber estado toda su vida en un lujoso hotel llamado Transylvania, y en el que su padre ha mantenido a algunos monstruos lejos de los seres humanos, de repente se ve sorprendida por un joven que, a su vez, se enamora de ella.

12 La ventaja de esta herramienta es que permite adjuntar imágenes y sonidos, y textos escritos por los usuarios. De esta manera, surgieron dieciocho videos con títulos como La bruja y el fantasma, Griffin y Mavis, Griffin y el lobo, Mavis se escapa, entre otros. 
Eisner: un apasionado por el ciclismo

Esta experiencia se basó en la idea de generar una narrativa transmedia entre estudiantes de grado noveno de tres colegios de la ciudad. Los estudiantes del primer colegio se encargaron de diseñar cuentos convencionales sobre la historia de vida de un compañero de clase que, recientemente, emigró de un municipio del departamento de Boyacá a Bogotá por factores asociados con la violencia. Eisner, seudónimo del protagonista, no solo es un estudiante que aún guarda costumbres de su lugar de procedencia, sino que, además, es un gran ciclista. Esta historia inspiró cerca de 25 cuentos en los estudiantes participantes.

La segunda narrativa fue desarrollada por estudiantes de otro colegio. Una vez conocieron las historias iniciales en redes sociales digitales y blogs, las tuvieron en cuenta para diseñar narrativas audiovisuales. Se produjeron 12 videos que escenifican la vida de Eisner, recrean su proceso migratorio, recuperan tradiciones y valores del mundo campesino, y generan imágenes y sonoridades que no solo dan cuenta del presente del protagonista, sino que también proponen mundos posibles sobre su futuro como ciclista profesional, ídolo de niños y jóvenes.

La tercera narrativa fue producida por estudiantes del tercer colegio. Con el apoyo del profesor de la asignatura Tecnología e Informática, diseñaron cinco animaciones digitales de manera colaborativa. Con el programa HTML5, los jóvenes introdujeron imágenes, escenas y paisajes sonoros para construir narrativas que expandieran lo alcanzado en las historias originales y en los videos.

\section{Análisis y discusión}

\section{Estilo de comunicación: bidireccionalidad, multitrayectoria y reticularidad}

En las dos experiencias pedagógicas, los profesores asumieron roles de mediadores, dado que orientaron procesos de construcción colectiva de conocimiento más que pretender la mecanización de los contenidos en sus estudiantes. La ruta de trabajo no estuvo estratégicamente predeterminada en ninguno de los dos casos. Sabían de entrada la lógica de producción de narrativas transmedia, pero no impusieron un camino único. Los estudiantes, al principio algo desubicados (especialmente los de secundaria), acogieron progresivamente el estilo comunicativo y se comprometieron en la producción narrativa propuesta.

En relación con el estilo comunicativo alcanzado por los niños de grado segundo, se destacan tres aspectos. En primer lugar, esta fue la experiencia en la que se dio con mayor naturalidad la bidireccionalidad entre emisores y receptores. La profesora daba las pautas generales y ellos respondían, preguntaban y hacían las actividades. De hecho, hubo un momento en el que la pauta empezó a ser proporcionada por un grupo de estudiantes, dado su conocimiento del filme y su capacidad para identificar las imágenes más adecuadas en función de la producción del video respectivo. Aunque algunos grupos tuvieron dificultad en la parte técnica, en especial con el uso de Calameo, otros los apoyaron y asumieron el rol de orientadores y mediadores.

El segundo aspecto que llamó la atención es el modo como circularon los mensajes dentro del grupo y fuera de este. El mensaje inicial fue instruccional y claramente convencional, el cual fue impartido por la profesora. Sin embargo, progresivamente el primer mensaje se convirtió en fuente de nuevos mensajes en los pequeños grupos y en el grupo en general. Luego, los mensajes paulatinamente abandonaron su carácter instrumental y estratégico para convertirse en contenidos digitales. Como se aprecia en las producciones de los estudiantes, hay un interés especial en producir contenidos que guardan relación estrecha entre el código analógico y la imagen. Este ejercicio potenció el proceso de lectura y escritura en el grupo. Aquí la imagen no fue un accesorio (ilustrar, ejemplificar...) sino algo constitutivo del mensaje. De hecho, los textos escritos están dentro de las imágenes.

El tercer aspecto está relacionado con los procesos de codificación y decodificación. Las producciones narrativas logradas (que se describirán en el segundo plano de análisis) definen un estilo comunicativo distinto entre los estudiantes y la profesora, y entre los estudiantes con los estudiantes. La temática no es dominio de la profesora: es un saber que se va construyendo en la práctica y que les permite intercambiar información de manera creciente. Por esta razón, se generan codificaciones y decodificaciones en medio de tramas que proceden de la narrativa original, pero que también se expanden a partir de la ficción narrativa.

En relación con la segunda experiencia pedagógica, el estilo comunicativo no solo alcanzó niveles de bidireccionalidad y multitrayectoria, sino que devino rizomático, dado el carácter colaborativo y polifónico del proyecto. Desde el inicio, los tres profesores del proyecto (ubicados en instituciones educativas distintas) se propusieron hacer distintas producciones transmedia con la participación de estudiantes del grado noveno de sus respectivos colegios.

Los estilos comunicativos fueron diversos. Por ejemplo, al inicio, en el colegio 1 hubo roles muy marcados entre el profesor (emisor) y los estudiantes (receptores). Sin embargo, la decisión en torno al protagonista de los relatos (Eisner), un compañero que había padecido muchas dificultades no solo 
en su lugar de origen, debido a hechos de violencia, sino en su tránsito a Bogotá, marcó una dinámica de comunicación muy distinta entre los participantes ${ }^{13}$.

En el colegio 2, los estudiantes se comprometieron con la creación de videos (documentales y videoclips) sobre la historia de Eisner. Un punto de partida fue asumir que los emisores principales eran los compañeros del colegio 1, quienes produjeron las narrativas originales. Esta comunicación se hizo desde una página de Facebook y un blog producido por los estudiantes del primer grupo. Aunque la profesora fungió inicialmente como un emisor predominante, progresivamente el estilo comunicativo pasó de la bidireccionalidad al rizoma. Esto dado que los vínculos informativos y comunicativos se dieron en distintas direcciones. Algunos pequeños grupos del colegio 2 se comunicaron con pequeños grupos del colegio 1. Así mismo, fue necesario el diálogo permanente entre pequeños grupos del colegio 2 para aclarar ideas, escribir guiones, preparar escenografías y hacer pruebas con actores, entre otras actividades.

Por último, en el colegio 3, que tenía como meta producir narrativas mediadas por animación digital (con HTML5), se consolidó un estilo comunicativo expansivo que transitó de lo bidireccional y lo rizomático a la hibridación. Una vez los estudiantes conocieron la producción de sus compañeros de los colegios 1 y 2, procedieron a diseñar una estrategia de comunicación que les permitiera cumplir el sentido de la narrativa transmedia, esto es, la generación de sesiones de trabajo en distintos tiempos y espacios para la planeación del proceso de producción y divulgación.

No obstante, vale señalar que la comunicación del profesor, como emisor principal, en algunos momentos fue predominante. Esto dado que la animación digital, con el programa elegido, requiere algunos conocimientos técnicos previos. Sin embargo, dado que no se trata de un lenguaje de programación en sentido estricto, los estudiantes rápidamente se convirtieron en multiplicadores del uso del programa. Esto hizo que los niveles de apropiación garantizaran un estilo de comunicación multitrayectoria, el cual estuvo mediado por un permanente proceso de experimentación que llevó a la creación.

Tratamiento de los contenidos: interpretación, apropiación e intervención (remediación e hibridación)

Este plano de análisis se centra en los contenidos con los que trabajaron estudiantes y profesores para generar procesos de aprendizaje. Como se mencionó, las dos experiencias plantearon como punto de partida el reconocimiento del carácter abierto y expandible del conocimiento. Esto exigió definir cuatro puntos de vista compartidos por los profesores participantes ${ }^{14}$.

13 En adelante, la producción del relato convencional (texto alfabético) implicaba profundizar en la vida de su compañero, indagar en qué consistía el ciclismo de ruta y conocer sobre la geografía física y humana del departamento de Boyacá (lugar de procedencia de Eisner). Esto generó una dinámica comunicativa predominantemente externa al aula. También implicó la organización de tiempos distintos a la rutina de las clases convencionales.

14 a) Los contenidos escolares pueden ser abordados a partir de distintas fuentes de información (más allá del texto escolar), que pueden proceder de medios analógicos y digitales. b) Estos contenidos deben ser seleccionados con criterios académicos, de modo que favorezcan su interpretación y apropiación. c) Los contenidos pueden ser intervenidos (remixados y remediados). d) Los contenidos pueden ser divulgados en audiencias interesadas en estos temas y problemas. 
Sobre la primera experiencia, se destacan varios aspectos del proceso de producción, tanto en la interacción con el contenido como en los modos de interpretación, apropiación y remediación. En relación con el primer proceso, los niños interpretaron la lógica de la narrativa e identificaron elementos como la trama, los personajes, los giros narrativos y los desenlaces. Este nivel de apropiación les permitió crear cuentos cortos con modificaciones al relato original. Por ejemplo, en algunos cuentos mantuvieron como protagonista a Mavis (hija del conde Drácula), mientras que en otros la historia giró alrededor de nuevos personajes. Esta narrativa también se destacó porque la aplicación permitió acompañar el texto de imágenes que identificaron en sitios abiertos de la web. De esta manera, los niños buscaron establecer correspondencia entre el texto escrito y las imágenes con el fin de darle profundidad a cada historia. Esto potenció la escritura y la lectura.

Imagen 1

Ejemplo de un cuento producido por niños de grado segundo

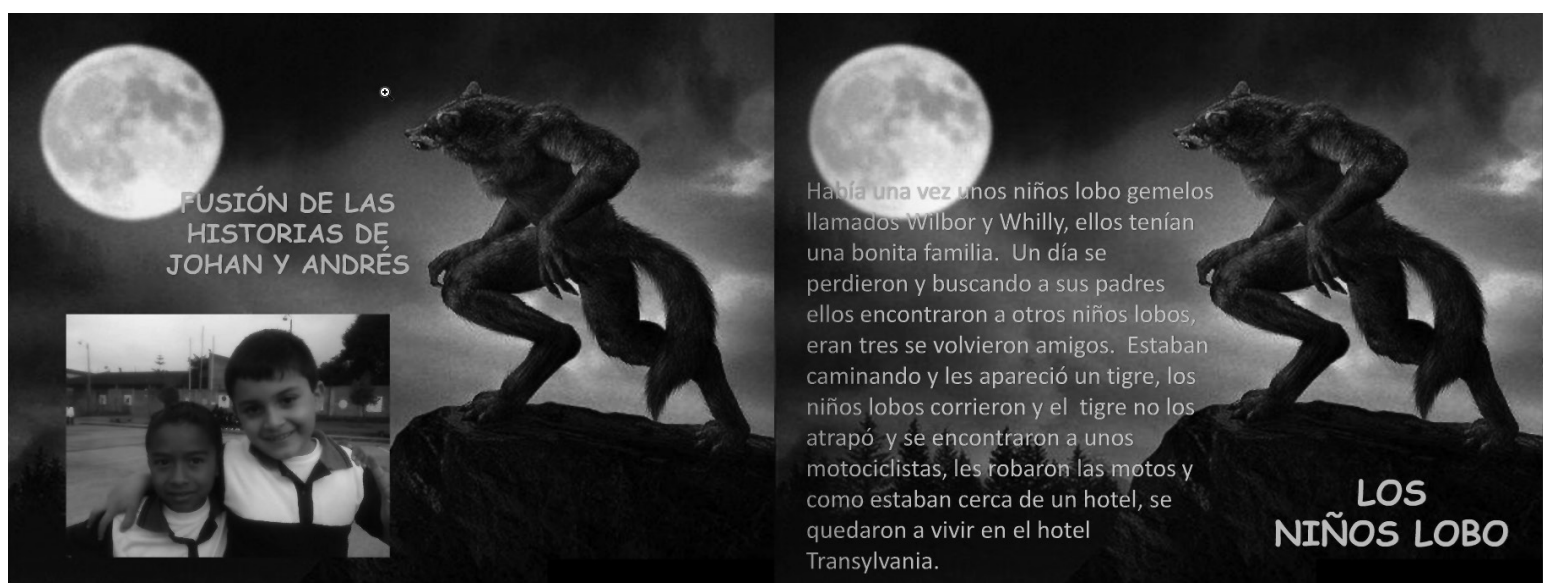

Fuente: Andrés Felipe Ortiz Camargo y Johan David Martínez Ávila. Estudiantes de grado segundo del I.E.D. Centro Integral José María Córdoba. Coordinación del trabajo en la institución educativa profesora Edna Irley Sánchez

En la segunda narrativa, los estudiantes tenían que diseñar un video con recursos que ofrece la herramienta, como imágenes, textos escritos y música ${ }^{15}$. Esto hizo que las historias adquirieran nuevas condiciones de producción y apropiación de los contenidos, pues para ellos y ellas la herramienta les ofrecía alternativas para caracterizar de manera más detallada a los personajes, así como maximizar elementos que configuran los hechos, la trama y los desenlaces. En el ejemplo presentado, los lobos (personajes principales) terminan convirtiéndose en futbolistas profesionales.

En la tercera narrativa, los estudiantes tuvieron que crear a los personajes que eligieron. Mediante la aplicación, ellos diseñaron los cuerpos, los rostros, las formas ficcionales de los monstruos respectivos, los dotaron de colores y de una posición que indujera al espectador a imaginar sus movimientos y sonidos. Con base en estas producciones, los estudiantes de grado segundo lograron responder al problema planteado por la profesora. Al interpretar y apropiar el contenido del filme, lograron generar

15 En esta herramienta (Storyboard), el movimiento no se produce en sentido estricto, como en la imagen audiovisual, pero los acercamientos y recorridos a cada imagen, junto a la música y el texto escrito, van dándole la impresión de acción al espectador. 
Imagen 2

Ejemplo de un video producido por niños de grado segundo
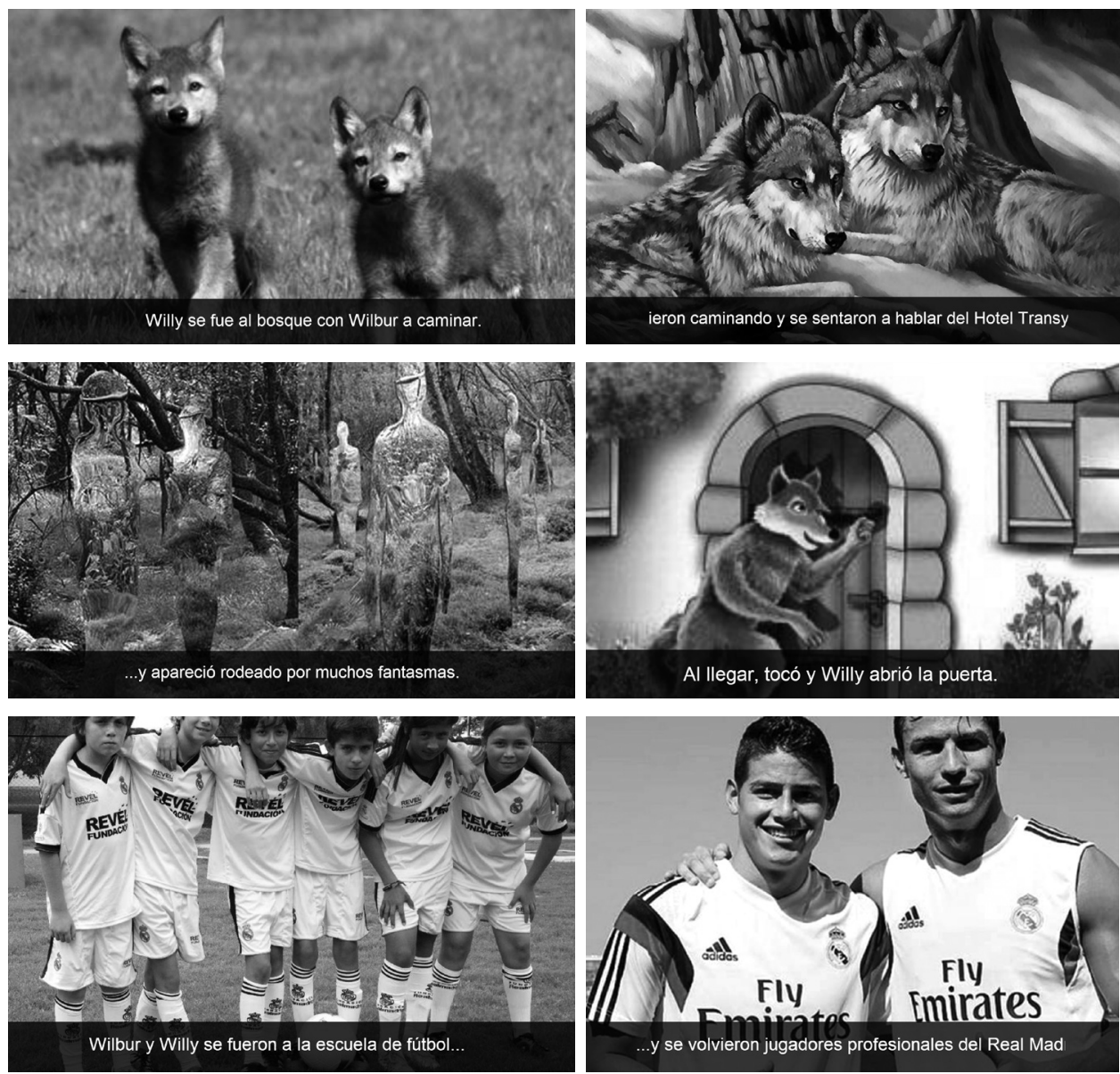

Fuente: Andrés Felipe Ortiz Camargo y Johan David Martínez Ávila. Estudiantes de grado segundo del I.E.D. Centro Integral José María Córdoba. Coordinación del trabajo en la institución educativa Edna Irley Sánchez

propuestas que ampliaron la trama original. Establecieron estrategias para crear contenidos que guardaron cierto nivel de coherencia con el original, pero que a su vez ampliaban las posibilidades de codificación y decodificación, a partir de una articulación permanente entre texto alfabético, imágenes y sonidos.

En relación con la propuesta en torno a la historia de Eisner, vale subrayar que, además de interpretar y apropiar los contenidos de las historias originales, los estudiantes también produjeron nuevas narrativas caracterizadas por incluir otras tramas, personajes, desenlaces y lenguajes. En particular, en la segunda narrativa se observaron varios procesos alusivos a la intervención, remediación y creación de contenidos. Por ejemplo, uno de los grupos planteó el diseño de un videoclip en el que se buscó destacar la grandeza y tenacidad de Eisner, al evidenciar que empezó a competir en una región de Boyacá hasta llegar a otros lugares, incluso fuera del planeta. A partir de esta idea, emplearon el cabezote del tráiler de un filme ( $L a$ guerra de las galaxias) y, mediante una aplicación, modificaron el audio del narrador (en inglés) e introdujeron textos (a manera de subtítulos en castellano) sobre la historia de Eisner. El producto es el "tráiler" de una película que está próxima a su lanzamiento oficial. 

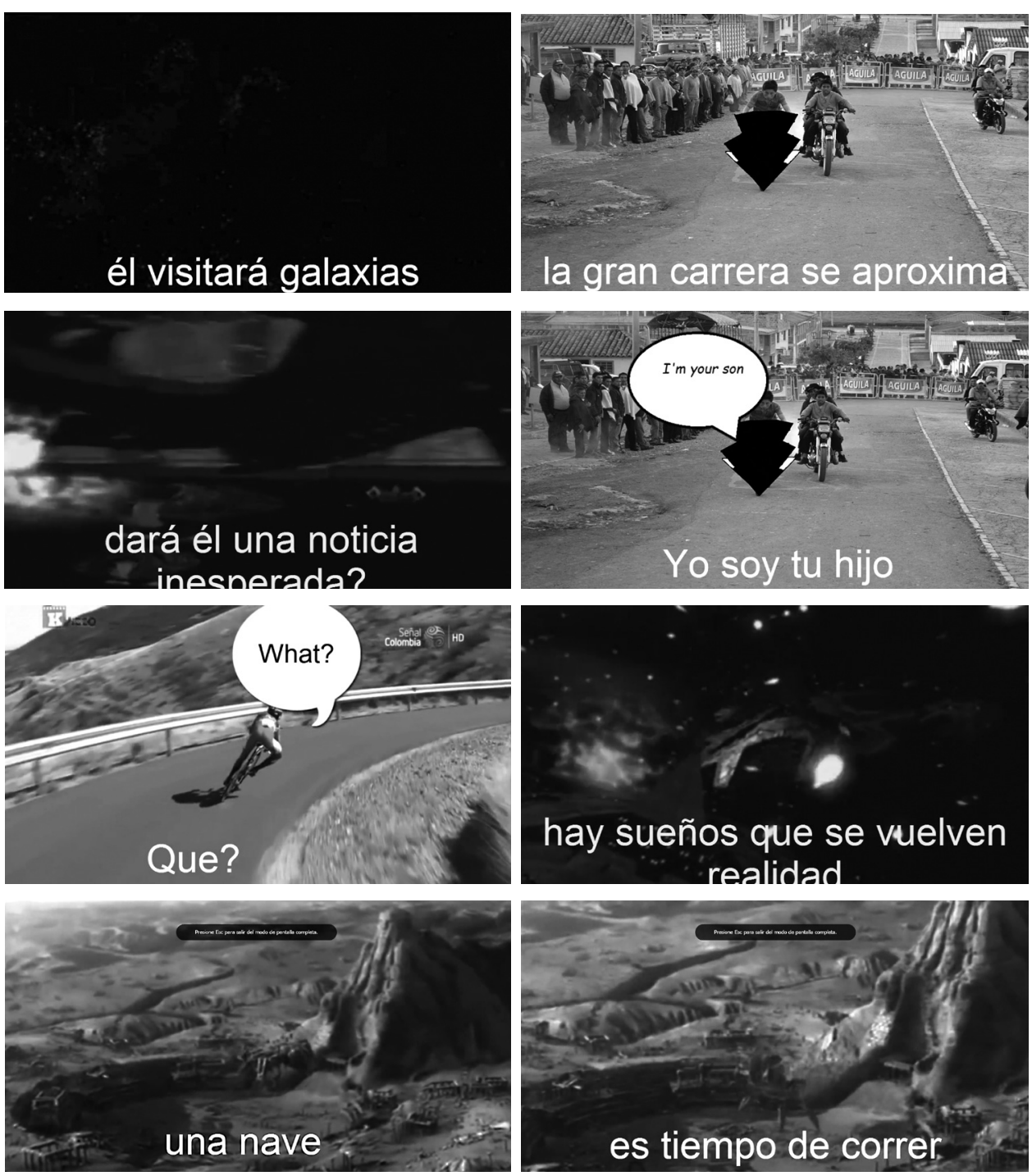

Fuente: Estudiantes de grado noveno del Taller Creativo del Colegio El Rodeo IED. Coordinación del trabajo en la institución educativa profesor Pedro Rivera

En esta remediación, los estudiantes se valieron de herramientas de la web, imágenes de una carrera de ciclismo de Nairo Quintana (campeón del Giro de Italia, 2014), fotografías alteradas de una carrera de ciclismo del personaje (Eisner) y escenas del filme La guerra de las galaxias. Teniendo en cuenta que las herramientas de trabajo son básicas, vale destacar el resultado alcanzado por el grupo. Adicionalmente, este video, junto con otros similares, fue publicado en la página de Facebook del grupo y en el canal del proyecto en YouTube.

Finalmente, la animación digital planteó un proceso de alta complejidad no solo en el proceso de producción, sino también por su capacidad de circulación y recepción. Dada la dificultad para producir una animación digital, las historias resultaron cortas; sin embargo, al articularlas con las demás producciones, la exposición resultó altamente significativa para el grupo. 


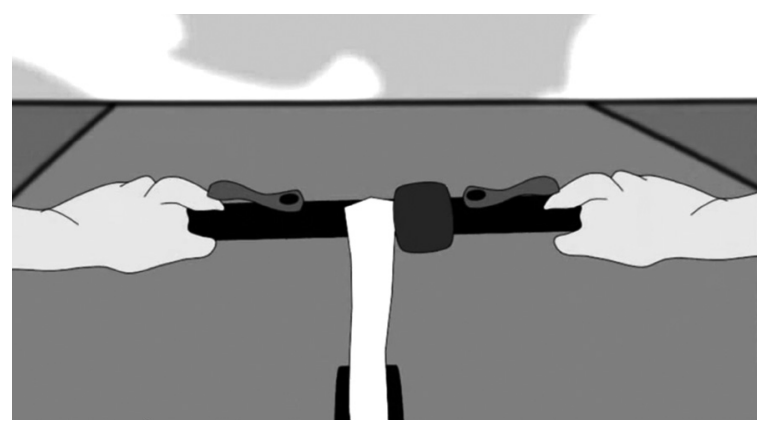

\section{INSTITUCION TECNICA SAN PEDRO DE IGUAQUE}
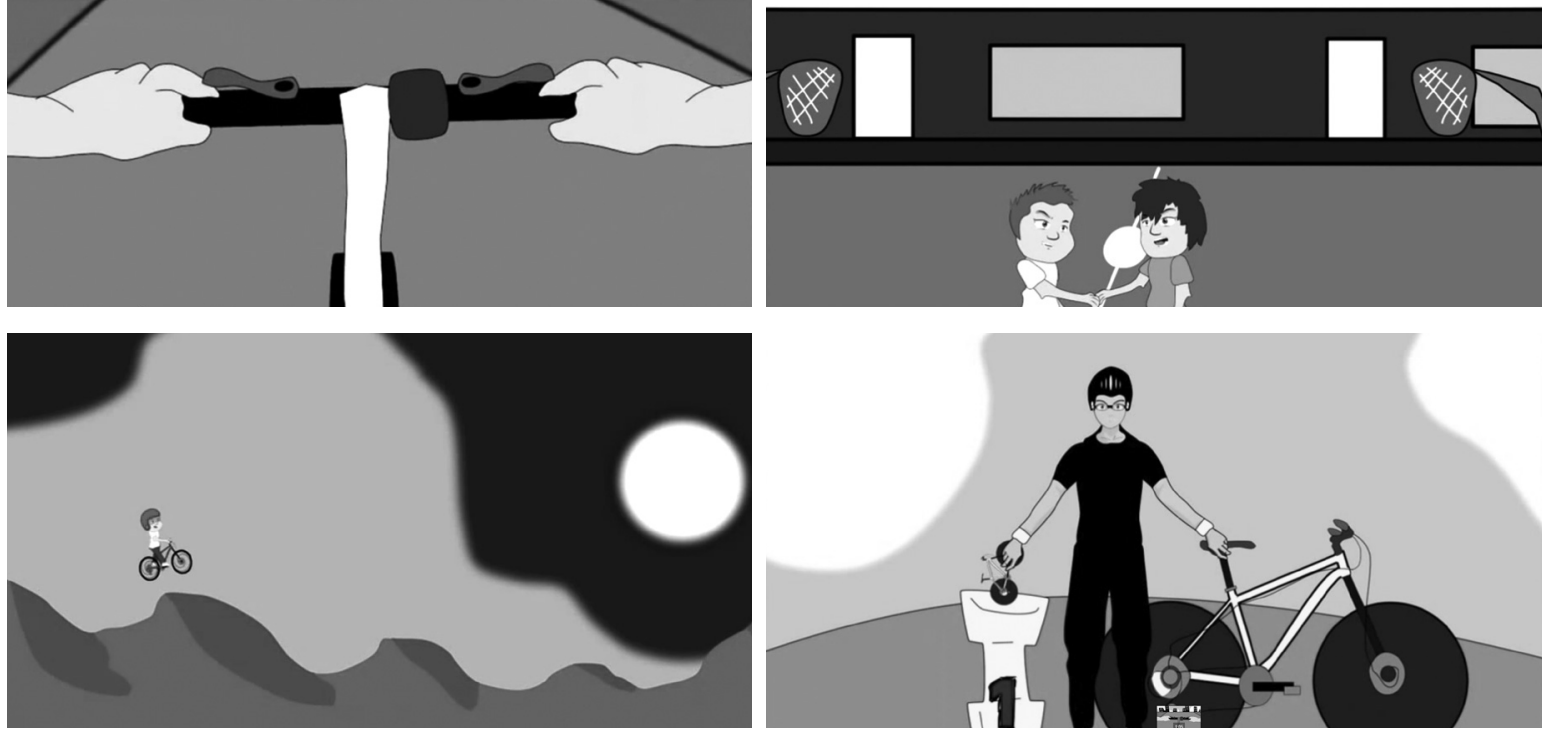

Fuente: Estudiantes de grado noveno del Taller Creativo del Colegio El Rodeo IED. Coordinación del trabajo en la institución educativa profesor Pedro Rivera

Además del carácter interactivo del contenido, el cual fue central en los procesos de reflexión individuales y colectivos, orientados por el profesor, los estudiantes analizaron las relaciones y diferencias entre las tres narrativas. Esto hizo que identificaran sus dificultades y avances ${ }^{16}$. También les permitió comprender que la producción de conocimiento alrededor de este proyecto fue posible gracias al trabajo de los compañeros del primero y segundo colegio. Su tarea, en adelante, será establecer estrategias para divulgar la producción de narrativas transmedia no solo de esta historia sino de otras historias. Esto teniendo en cuenta, según señalaron, que en los colegios de Bogotá hay héroes como Eisner que pronto tendrán que ser descubiertos y dados a conocer.

\section{Conclusiones}

El tránsito de la comunicación de masas a la comunicación digital interactiva (Scolari, 2008) ha hecho que las generaciones más jóvenes, aquellas que han crecido a la par con estas mutaciones socioculturales, se incorporen en otras formas de socialización, sensibilización y producción de saber. Esta realidad exige interpelar el modelo de comunicación de la escuela moderna, tanto en el predominio de un emisor (profesor) portador y administrador del mensaje como en el tratamiento de los contenidos

16 Entre las dificultades, los estudiantes manifestaron que no todos conocían los programas y las aplicaciones para el desarrollo de las actividades. En otros casos, mencionaron la ausencia de software en los computadores o tabletas del colegio, lo cual les afectaba sus tareas en la producción de las narrativas transmedia. Por último, algunos afirmaron que no estaban acostumbrados a desarrollar actividades de manera autónoma y que, en ocasiones, extrañaban que el profesor guiara la clase de manera convencional. 
escolares. Esto teniendo en cuenta que el saber es una construcción abierta, en red y susceptible de ser modificado, a partir de quienes lo usen ${ }^{17}$.

Los resultados de la investigación muestran que la educación interactiva es posible cuando se generan otros estilos comunicativos entre los actores (o interactuantes, según Aparici \& Silva, 2012). Es una educación que se puede desplegar cuando se trabajan de manera distinta los contenidos de aprendizaje, lo cual requiere de posibilidades para que los estudiantes no solo consuman sino para que intervengan y produzcan contenidos. Al respecto, Roberto Aparici y Marco Silva (2012) proponen un modelo de comunicación feed-feed, en oposición al feed-back. En este estilo, los participantes se alimentan comunicacional e informativamente todos con todos. Más que un proceso de refuerzo de mensajes, es un acto de construcción y de conexión entre los actores, en el cual todos tienen el mismo estatus, solo que distintos roles, independientemente del tipo de enunciación que se realice.

La experiencia pedagógica adelantada con los niños de grado segundo (Cuentos fantasmagóricos) muestra que desde temprano los procesos lectoescritores pueden ser promovidos a partir de ejercicios sencillos de transmediación. La experiencia pedagógica evidencia que la producción escrita se incrementa cuando los estudiantes trabajan, a manera de editores, productores y autores (Henao-Álvarez \& Ramírez, 2010). Al respecto, queda por explorar la potencia que tiene la adquisición del signo alfabético cuando se trabaja simultáneamente con otras textualidades. En este caso, los estudiantes incrementaron su capacidad de escritura cuando el código se introdujo en las imágenes y las sonoridades. La imagen no fue un accesorio, fue algo constitutivo del contenido producido por ellos (Ferrés, 2014).

En la experiencia pedagógica adelantada con estudiantes de secundaria de tres colegios oficiales de Bogotá (Eisner, un apasionado por el ciclismo), se evidenció que la comunicación implementada replanteó la lógica de emisores y receptores para introducir modos de comunicación predominantemente reticulares y rizomáticos. Esto teniendo en cuenta que el proyecto se desarrolló entre tres colegios, cada uno con responsabilidades específicas en torno al proceso de creación. Por otro lado, los estudiantes lograron expandir la narrativa no solo con el formato video sino también mediante la animación digital. Estos procesos exigieron no solo dominar técnicas de diseño, sino también indagar aspectos socioculturales, geográficos y políticos en torno al personaje, lo cual fue resignificado a partir de la indagación de datos de la realidad y de la producción de ficciones individuales y colectivas. Es una producción de contenidos que pasa por la remediación y que se consolida por medio de la hibridación, como se observa en el videoclip (tráiler, lanzamiento de la obra).

Vale aclarar que, dada la delimitación de la investigación, aún están pendientes varios procesos por indagar, a propósito de la posibilidad de posicionar las apuestas de la educación interactiva en la escuela.

17 Dado que en este estilo de comunicación no solo hay consumidores de contenidos sino también productores, esto es, "prosumidores", una de las expresiones contemporáneas que favorecen esta cultura de participación es la narrativa transmedia. Los usos y apropiaciones de este tipo de narrativas hacen que las personas se habitúen a la intervención del contenido y, por consiguiente, a la producción de alternativas textuales (storytelling). Con herramientas libres de la web, y otras de carácter restringido, los usuarios pueden alterar los contenidos, así como proponer alternativas a la trama de las historias, dotar de rasgos distintos a los personajes, producir giros a las problematizaciones y arriesgar finales diferentes de las obras. En suma, se trata de una forma de aprender atendiendo al carácter narrativo - más que paradigmático- del pensamiento (Bruner, 2004). 
Por ejemplo, es necesario profundizar cómo se dan los procesos de participación, cooperación y colaboración entre estudiantes. Se requiere indagar los modos de razonamiento de los estudiantes a partir de nuevos estilos de comunicación en los ambientes de aprendizaje, mediados por narrativas más complejas (hipertexto, hipermedia, transmedia). Es fundamental analizar los procesos de aprendizaje, bajo estas condiciones, en áreas como las ciencias sociales, las ciencias naturales y las matemáticas. Por último, es necesario investigar cómo se da el reconocimiento de las diferencias (identidades y subjetividades) entre los interactores cuando se fomentan estilos de comunicación interactivos.

\section{Agradecimientos}

Profesores de la SED Bogotá participantes de la Maestría en Comunicación-Educación de la Universidad Distrital.

\section{Sobre el autor}

Juan Carlos Amador-Baquiro es doctor en educación y licenciado en ciencias sociales. Profesor en la Facultad de Ciencias y Educación de la Universidad Distrital Francisco José de Caldas. Integrante del Grupo de Investigación Jóvenes, Culturas y Poderes.

\section{Referencias}

Amador, Juan Carlos (2013). Aprendizaje transmedia en la era de la convergencia cultural interactiva. Educación y Ciudad, 25, 11-24. Disponible en: http://www.idep.edu.co/revistas/index.php/ educacion-y-ciudad/article/view/50/41

Aparici, Roberto (2010). Introducción, Conectividad en el ciberespacio. En Roberto Aparici (coord.). Conectados en el ciberespacio, 9-26. Madrid: Universidad Nacional de Educación a Distancia, UNED.

Aparici, Roberto \& Silva, Marco (2012). Pedagogía de la interactividad. Comunicar, 19 (38), 51-58. Disponible en: https://www.revistacomunicar.com/ pdf/preprint/38/05-PRE-12698.pdf

Blumer, Herbert (1982). El interaccionismo simbólico. Perspectiva y método. Madrid: Editorial Hora.

Bolter, Jay David \& Grusin, Richard (2000). Remediation. Understanding New Media. Cambridge, Massachusetts: MIT Press.

Bruner, Jerome (2004). Realidad mental y mundos posibles: los actos de la imaginación que dan sentido a la experiencia. Barcelona: Gedisa Editorial.

Burbules, Nicholas C. (2006). Educación: riesgos y promesas de las nuevas tecnologías de la información. Buenos Aires: Editorial Granica.
Cabero, Julio (2001). Las nuevas tecnologías en el aula. ¿Una realidad o una utopía? En Jesús RodríguezBriones, Carlos Hervás-Gómez, Urbano Jesús Muñozs-Pedroche (coords.), Federación de Trabajadores de la Enseñanza, Unión General de Trabajadores, Grupo de Investigación Didáctica, FETE-UGT, GID. Nuevas tecnologías aplicadas a la educación, 1-11. Sevilla: Ed. Universidad de Sevilla. Texto disponible en: http://www.grupo tecnologiaeducativa.es/images/bibliovir/89.pdf

Cobo-Romaní, Cristóbal \& Moravec, John W. (2011). Aprendizaje invisible. Hacia una nueva ecología de la educación. Barcelona: Collecció Transmedia XXI. Laboratori de Mitjans Interactius / Publicacions i Edicions de la Universitat de Barcelona. Disponible en: https://educationfutures.com/books/ aprendizajeinvisible/download/Aprendizajelnvi sible.pdf

Costalat-Founeau, Anne-Marie (1985). De l'interaction à l'interactivité. La nécessité d'une refonte conceptuelle. Interactivité (s). Dérive d'une notion. Lieux et outils. Les usages sociaux. Du praxéologique à l'imaginaire création (s), écriture (s). De nouveaux modèles. Bulletin de I'IDATE, Institut de l'audiovisuel et des télécoms en Europe, 20, 245-249.

Dussel, Inés \& Gutiérrez, Daniela (comps.) (2006). Educar la mirada. Políticas y pedagogías de la imagen. Buenos Aires: Manantial, Facultad Latinoamericana de Ciencias Sociales, Flacso. Disponible en: http://nuestraescuela.educacion.gov.ar/ban coderecursos/media/docs/apoyo/apoyo04.pdf

Ferrés i Prats, Joan (2008). La educación como industria del deseo. Un nuevo estilo comunicativo. Barcelona: Editorial Gedisa.

Ferrés i Prats, Joan (2014). Las pantallas y el cerebro emocional. Barcelona: Editorial Gedisa.

Gadotti, Moacir (2011). Historia de las ideas pedagógicas. México: Siglo XXI.

Goffman, Erving (2012). La presentación de la persona en la vida cotidiana. Buenos Aires: Editorial Amorrortu.

Guber, Rosana (2001). La etnografía. Método, campo y reflexividad. Bogotá: Editorial Norma.

Henao-Álvarez, Octavio \& Ramírez, Doris Adriana (2010). Cómo orientar la escritura en la escuela. Medellín: Editorial Universidad de Antioquia. Disponible en: https://issuu.com/reddebiblio tecas/docs/como_orientar_la_escritura_en_la_ escuela

Hine, Christine (2002). Etnografía virtual. Barcelona: Editorial de la Universitat Oberta de Catalunya, Editorial UOC. Disponible en: https://seminariosocioantropologia.files.wordpress.com/2014/03/ hine-christine-etnografia-virtual-uoc.pdf 
Huergo, Jorge A. (2000). Comunicación/Educación. Itinerarios transversales. En Carlos Eduardo Valderrama (ed.). Comunicación- Educación, coordenadas, abordajes y travesías, 3-25. Bogotá: Universidad Central, Departamento de Investigaciones de la Universidad Central, DIUC, Siglo del Hombre Editores, Serie Encuentros.

Jenkins, Henry (2008). Convergence Culture. La cultura de la convergencia de los medios de comunicación. Barcelona: Editorial Paidós. Disponible en: https://stbngtrrz.files.wordpress.com/2012/10/jenkins-henryconvergence-culture.pdf

Kaplún, Mario (1998). Una pedagogía de la comunicación. Madrid: Editorial La Torre.

Kinder, Marsha (1991). Playing with Power in Movies, Television, and Video Games: from Muppet Babies to Teenage Mutant Ninja Turtles. Berkeley: University of California Press.

Lacasa, Pilar (2011). Los videojuegos. Aprender en mundos reales y virtuales. Barcelona: Editorial Morata.

Lévy, Pierre (2007). Cibercultura. La cultura de la sociedad digital. Barcelona: Anthropos, Universidad Autónoma Metropolitana.

Martín-Barbero, Jesús (2003). De los medios a las mediaciones. Comunicación, cultura y hegemonía. Bogotá: Convenio Andrés Bello.

Mead, George H. (1968). Espíritu, persona y sociedad. Buenos Aires: Paidós Editorial.

Medina, Manuel (2007). Prólogo. En Pierre Lévy. Cibercultura, la sociedad digital, 7-24. Barcelona: Anthropos.

Multigner, Gilles (1994). ¿Sociedad interactiva o sociedad programada? En Rosa María de la Parra (dir.). Apuntes de la sociedad interactiva: autopistas inteligentes y negocios multimedia, 421-428. Madrid: Editorial Universidad Internacional Menéndez Pelayo.

Orozco-Gómez, Guillermo (2010). Entre pantallas: nuevos roles comunicativos y educativos de los ciudadanos. En Roberto Aparici (comp.). Educomunicación: más allá del 2.0, 267-280. Barcelona: Gedisa Editorial.

Piscitelli, Alejandro (2009). Nativos digitales, dieta cognitiva, inteligencias colectivas y arquitecturas de participación. Montevideo: Editorial Santillana.

Rodríguez, Jaime Alejandro (2011). Narrativas del ciberespacio. En Jaime Alejandro Rodríguez (ed.). Narratopedia. Reflexiones sobre narrativa digital, creación colectiva y cibercultura, 39-68. Bogotá: Pontificia Universidad Javeriana. Disponible en: http://cmap.javeriana.edu.co/servlet/ SBReadResourceServlet? rid=1303831059858_1957124121_3174

Rueda-Ortiz, Rocío (2009). Convergencia tecnológica: síntesis o multiplicidad política y cultural. Revista Signo y Pensamiento, 28 (54), 114-130. Disponible en: http://www.redalyc.org/pdf/860/86011409008.pdf

Scolari, Carlos Alberto (2008). Hipermediaciones. Elementos para una teoría de la comunicación digital interactiva. Barcelona: Editorial Gedisa.

Scolari, Carlos Alberto (2013). Narrativas transmedia. Cuando todos los medios cuentan. Barcelona: Editorial Planeta.

Silva, Marco (2005). Educación interactiva. Enseñanza y aprendizaje presencial y on-line. Barcelona: Gedisa Editorial.

Wenger, Etienne (2003). Comunidades de práctica. Aprendizaje significativo e identidad. Barcelona: Paidós. 